\title{
13. Arithmetic using COMPUTE
}

Data items which are going to be used in arithmetic must be stored in numeric fields. The fields declared in the Data Division must also be large enough to hold the numbers being used - be particularly careful about the length of the field that will hold the answer.

The computer can be instructed to perform arithmetic using the COMPUTE command - followed by the arithmetic expression.

e.g. COMPUTE TOTAL-WAGE = BASIC-WAGE + OVERTIME-PAY - TAX.

The sum is performed and the answer placed in TOTAL-WAGE.

The arithmetic signs are:

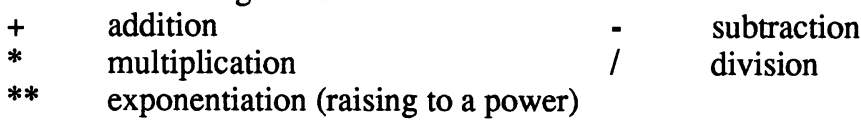

The normal rules apply as to the order in which arithmetic operations are carried out (i.e. EXPONENTIATION is done first, followed by MULTIPLY and DIVIDE, followed by PLUS and MINUS ) - e.g. -

COMPUTE $\mathrm{X}=\mathrm{A}+\mathrm{B} * \mathrm{C}$ means first multiply $\mathrm{B}$ by $\mathrm{C}$ and add $\mathrm{A}$ to the answer.

This order can be changed by using brackets () around parts of an expression which are to be calculated first - e.g.-

COMPUTE $\mathrm{X}=(\mathrm{A}+\mathrm{B}) * \mathrm{C}$ means first add A to B and multiply the answer by C.

\section{NOTE THE SPACING BETWEEN WORDS AND SYMBOLS}

\section{Exercises}

1. Looking at the example program on lesson 5 - why has ANSWER been defined as two digits long?

2. Write programs:

a) to ask for a student's NAME, MATHS-MARK, ENGLISHMARK and COMPUTING-MARK and then display his NAME and AVERAGE-MARK.

b) to ask for an employee's NAME and ANNUAL-PAY; calculate TAX-FOR-YEAR at $30 \%$ of pay; work out NET-ANNUAL-PAY and finally display a payslip showing NAME, GROSS-WEEKLY-PAY, TAXFOR-WEEK and NET-WEEKLY-PAY.

c) to ask for an employee's NAME and WAGE; then give him an increase of $20 \%$ and print out the NAME and NEW-WAGE.

d) to ask for the figure for the TOTAL-BONUS to be divided among staff, and the NUMBER-OF-STAFF; then display the amount of BONUSFOR-EACH-EMPLOYEE.

e) to ask for the LENGTH and WIDTH of a room;then calculate the FLOOR-AREA and display all the room's measurements. 